\title{
Effects of COVID-19 during lockdown in Nepal
}

\author{
Preeti Mahato ${ }^{1}$, Pasang Tamang ${ }^{2}$, Prakash Shahi ${ }^{3}$, Nirmal Aryal ${ }^{1}$, Pramod Regmi ${ }^{1}$, Edwin van \\ Teijlingen ${ }^{1-4,5}$, Padam Simkhada ${ }^{2-4,5}$
}

\author{
Author Info: \\ ${ }^{1}$ Faculty of Health and Social \\ Sciences, Bournemouth \\ University, UK
}

\section{${ }^{2} \mathrm{School}$ of Human and Health Sciences, University of Huddersfield, UK}

\section{${ }^{3}$ Manavta, Research and Development, Nepal}

${ }^{4}$ Manmohan Memorial Institute of Health Sciences, Tribhuvan University, Nepal

${ }^{5}$ Nobel College, Pokhara University, Nepal

\section{Corresponding Author:}

Mr. Prakash Shahi

Email/Contact:

prakash@manavtaproject.org

\section{ABSTRACT}

Nepal started its full lockdown on March 24, 2020 and has been extended until 14 June 2020 as a precaution for prevention of COVID-19 infection. However, the strict lockdown has been criticised by many as not all the deaths are caused by COVID-19. The long and strict lockdown have had some negative effects in many aspects of health of an individual in the community. Many women are facing barriers to access maternity health care during the lockdown period and there has been rise in the suicidal behaviour such as sucidal attempt and actual suicide itself among the general population. As the lockdown began in Nepal, all the school and colleges were suspended, and children were forced to spend their time indoors and exams has been postponed leaving the students stressed about the uncertainty of their future. Social distancing, isolation and quarantine at home can result in isolated in an abusive home where there could be even more increase in abuse during such crisis. Millions of babies are missing the routine vaccinations which is a threat to global achievement in immunization. Apart from the rise in negative impact on health of Nepali people, there are other impacts related to health such as serious impacts on logistics and supply management including shortage of medicine and food supply; and impacts on farming including both production and sale. Nepal took several precautionary measures as a response towards COVID-19 such as First, limiting international air travel, sealing the land border-crossings with India and introduction of social distancing measures. However, with rise in deaths due to non COVID related causes and negative impacts on economic and financial condition of the country, there is a need for the country to ease its lockdown. Contact tracing, making face mask mandatory along with social distancing measure can be an alternative to lockdown for Nepal while the country is preparing to ease its lockdown. Social distancing, hygiene, lifestyle factors and PPE measures need to continue for long term, whilst we need to keep working on the big public health issues such as poverty reduction, improving access to health service to achieve universal health coverage.

Keywords: COVID-19 in Nepal, Effects of Lockdown, Quarantine,

\begin{tabular}{|c|cc|}
\hline $\begin{array}{c}\text { QR Code } \\
\text { Scan Me for }\end{array}$ & $\begin{array}{c}\text { Received: } 3 \text { June 2020; } \\
\text { Full Text }\end{array}$ \\
How to cite this article in Vancouver Style? & Published Online: 11 June 2020 \\
Mahato P, Tamang P, Simkhada P, Shahi P, Teijlingen E van, Aryal N, Regmi P. Effects of COVID-19 during lockdown \\
in Nepal. Europasian J Med Sci.2020;2(Covid-19 Special Issue): 105-10. \\
https://doi.org/10.46405/ejms.v2i2.91
\end{tabular}




\section{INTRODUCTION}

Nepal reported its first COVID-19 case on January 30, 2020 and until March 28 there were just five reported cases. ${ }^{1,2}$ The latest figure shows there are a total of 2300 cases of COVID-19 as of June 3, 2020 with 9 deaths and 278 recovered. ${ }^{3}$ Nepal started its full lockdown on March 24, and currently it has extended its lockdown until 14 June. ${ }^{4}$ The strict lockdown has been criticised by many and has been the cause for many deaths not related to COVID-19. ${ }^{5}$ While there are only nine deaths caused directly by COVID-19 in Nepal, there are hundreds of deaths caused due to other indirect factors linked to the COVID-19 Pandemic. In this article, we have highlighted some negative effects of the long and strict lockdown and we suggest ways in which the country could ease the lockdown.

Effects on maternity services and rise in maternal deaths

The percentage of births attended by skilled birth attendants in Nepal before the pandemic was only $58 \%$ according to the Ministry of Health. ${ }^{6}$ This proportion has dropped during this pandemic as pregnant women are facing more barriers to accessing maternal health care. ${ }^{7}$ The maternity services have been obstructed during this lockdown and there has been a lack of transportation services resulting in a $200 \%$ increase in maternal mortality rate since the lockdown began. ${ }^{8,9}$ Many women are forced to give birth at home or die on the way to health facilities. ${ }^{8} \mathrm{Nepal}$ is still a long way to achieve its 2030 Sustainable Development Goal's (SDG) target of reducing its maternal mortality ratio (MMR) and the ongoing lockdown with limited access to health care services, is only going to make things worse. ${ }^{9}$

\section{Effects on mental health and rise in suicide cases}

Perhaps the greatest effect of lockdown has been on mental health of people globally. Nepal Police have reported a total of 875 people nationally, a rise in $20 \%$, who have committed suicide during lockdown. ${ }^{10}$ The World Health Organization (WHO) had warned about increase in anxiety, stress, loneliness, depression, harmful alcohol and drug use, and self-harm or suicidal behaviour. ${ }^{11}$ These are the common features of typical mental ill health that many may experience during and after the crisis. ${ }^{12}$ These mental health issues could lead to suicidal behaviours such as suicidal attempts and actual suicide in extreme cases. A 36-year-old
Bangladeshi man committed suicide by hanging himself from a tree near his house on March 5, 2020 because he and the people in his village thought he was infected with COVID-19 based on his fever and cold symptoms and his weight loss which later on autopsy showed that the victim did not have COVID-19. ${ }^{13} \mathrm{~A}$ very similar case was reported in India on February 12 (2020), where the victim, returning from a city to his native village, committed suicide by hanging to avoid spreading COVID-19 throughout the village. ${ }^{13,14}$ It shows that the fear and misconceptions regarding COVID-19 among poorly educated people in rural areas are contributing to increased suicide rates..$^{13}$ It is therefore very important to consider the mental and psychosocial health during lockdown and to make people aware of the facts of the COVID-19 to avoid misconceptions.

\section{Effects on children and adolescents}

As the lockdown began in Nepal, all the school and colleges were suspended, and children were forced to spend their time indoors. School routines are important coping mechanisms for children with special needs and closure of schools means a lack of access to resources they usually have at the school. ${ }^{15}$ The higher secondary level exams in Nepal have been postponed meaning the adolescents could find themselves more stressed because of the uncertainty of their future. A poll conducted among secondary level students in lockdown in Hong Kong found over $20 \%$ students reported that their stress levels were at maximum. ${ }^{15}$

\section{Rise in domestic violence}

Coronavirus has changed lots of things about family life. Social distancing, isolation and quarantine at home can result in isolated in an abusive home where there could be even more increase in abuse during such crisis. ${ }^{15}$ Conflict, stress and spending more time with one another can cause arguments and can be difficult to keep children shielded from adult arguments when everyone is together most of the day. ${ }^{16}$ This can be very serious for the mental health of the children. Self-isolation and lockdown measures also increase the risk of children, in particular girls, becoming the victims of domestic violence, online bullying or other forms of abuse. ${ }^{17}$ The lockdown due to the COVID-19 has led to a sharp spike in the number of women reporting incidents of domestic abuse across the world, for example in India and Singapore calls to domestic 
violence hotlines have increased dramatically. ${ }^{17}$ Similarly, in Nepal since the lockdown was implemented, the national helpline reported 1145 calls related to gender-based violence which is about 20 calls every day, with more than one in five specifically about domestic violence. ${ }^{18}$ The Women's Rehabilitation Centre (WOREC), an organisation working to combat violence against women and children, reported 336 cases of violence against women and girls from 33 districts of Nepal during the lockdown period (24 March-15 May 2020) and mostly commonly experienced by women of the age group 17-35 years (211 cases in total). Figure 1 shows that 198 cases were domestic violence. Most perpetrators to commit violence against women are husbands, followed by family members and neighbours. ${ }^{19}$

\section{Impact on Routine Health Services: Child health and Immunization}

COVID-19 is a threat to global achievement in immunization. Experts have warned millions of children could die from preventable disease because of the disruption to vaccination programmes caused by COVID-19. At least 68 countries have experienced disruptions to their vaccination campaigns, and it is estimated that in South East Asia 34.8 million babies are missing routine vaccinations because of COVID-19.20
On May 21, 2020 Ministry of Health and Population, Nepal endorsed Interim guideline on reproductive maternal, newborn and child health (RMNCH) services in COVID-19 Pandemic. ${ }^{21}$ The guideline has highlighted the following services for child health and immunization;

- physical distance for providing immunization services

- Assess the child before providing immunization

- Protection of service providers

- Coordination for providing immunisation services for targeted children

- Coordinate with relevant administrative official at the local level

- Orient local administrative officials and stakeholders about physical distancing, need of immunization services, roles and responsibilities of health care providers for COVID 19 prevention.

Lockdown is a key component of Nepal's policy approach to COVID-19 and as a result routine immunisations have been severely disrupted and there have been sporadic outbreaks of vaccinepreventable diseases i.e. measles and diphtheria in parts of Nepal. ${ }^{22}$ The analysis by researchers from the John Hopkins Bloomberg School of Public Health estimates that globally 1.2 million underfive deaths could occur in just six months as well as an increase in child wastina, due to reductions in

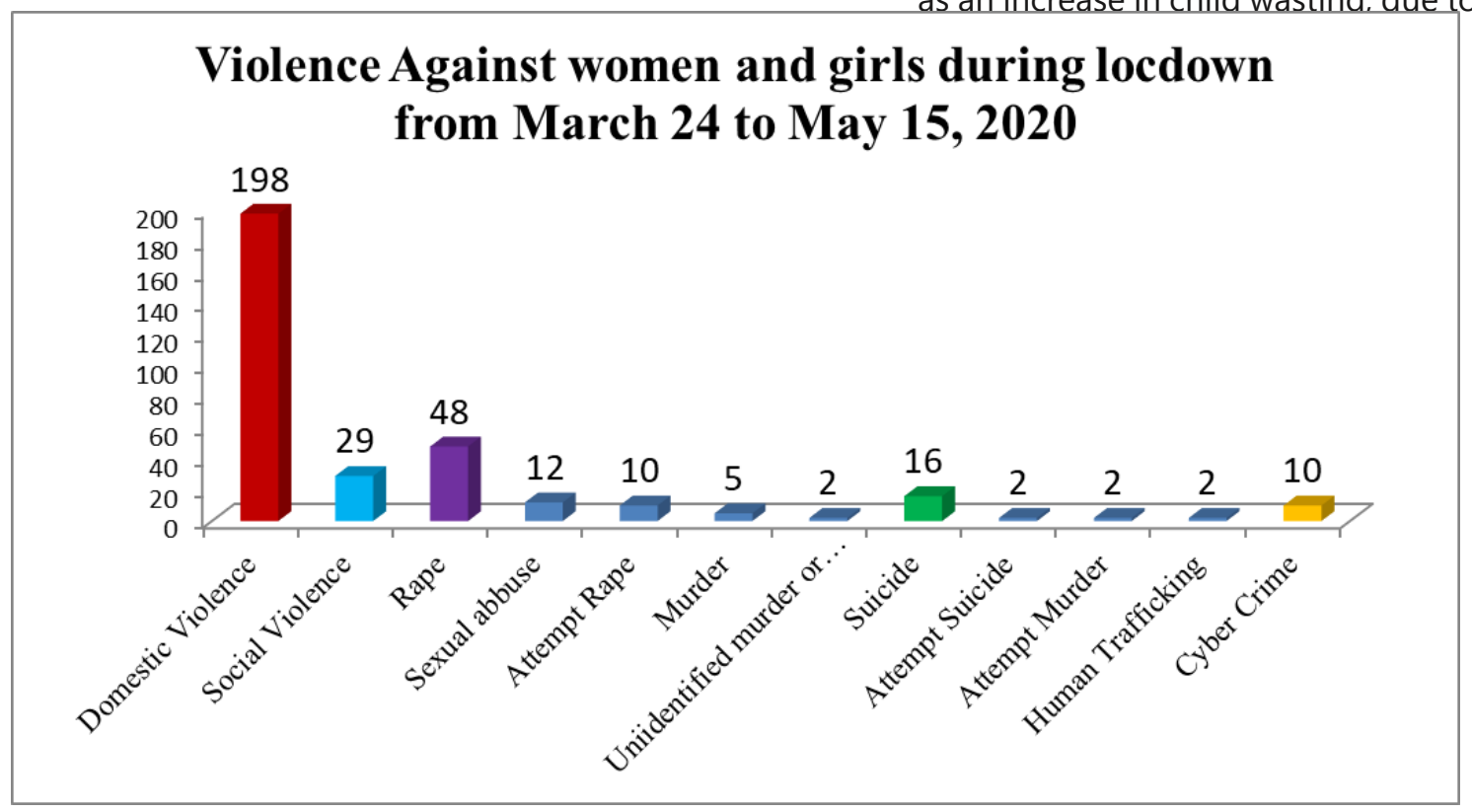

Figure 1: Lockdown related cases of violence against women and girls $(n=336)$ reported by WOREC 
routine health services. In the next six months up to 4,000 children could die in Nepal alone. ${ }^{23}$

\section{Other impacts}

Apart from the rise in negative impact on health of Nepali people, there are other impacts related to health such as serious impacts on logistics and supply management including shortage of medicine and food supply; and impacts on farming including both production and sale. There are reports of people dying due to shortage of medicine supply such as for heart patient especially in rural parts of Nepal. ${ }^{24}$ Similarly, COVID-19 is putting Nepal's small-scale producers and landless farmers under strain. The big issue for farmers is not production but means of selling their goods. ${ }^{25}$ The World Bank warns that the pandemic will hit low-income people hard and a protracted COVID-19 crisis including long and strict lockdown may threaten food security especially for the most vulnerable. ${ }^{26}$

\section{Public health strategy to tackle COVID-19 in Nepal}

Nepal took several precautionary measures as a response towards COVID-19. First, the government began limiting international air travel from affected countries in February and later from the rest of the world. Secondly, the land border-crossings with India were sealed on March 24. Thirdly, social distancing measures were introduced in the middle of March when the schools were closed, and exams cancelled. Fourthly, on 24 March, the country imposed a nationwide lockdown and currently is extended until June 14 and International flights remain suspended until the end of June., ${ }^{4,27}$ As the lockdown cannot go for very long time, there is a need for preparing for other preventative measures that can eventually replace the lockdown. ${ }^{28}$

The country has recently published its 'Health Sector Emergency Response Plan- COVID-19 pandemic' in May. It has outlined the planning and key strategies to deal with current crisis including quarantine management, case investigation and contact tracing, screening at point of entries, community level screening and testing, hospitalbased interventions, strengthening laboratory capacity and so on. ${ }^{29}$ The document has also focused on safety and security of frontline staff including availability of protective equipment to all health workers involved with tackling COVID-19. While the document looks comprehensive, the real challenge is its implementation.

\section{Purpose of lockdown and when it should be relaxed}

The purpose of a lockdown is to delay the spread of the pandemic with a reduced epidemic peak (so-called flattening the curve). However, there are potential negative impacts of lockdown such as economic mayhem, with many people dying from consequences of economic and financial hardship. ${ }^{30}$ This measure helps to buy time for preparing the implementation of other strategies to tackle the pandemic. An epidemiological modelling study conducted in Kathmandu found that in a resource-limited setting such as Nepal, a combination of early and aggressive case finding is best with physical distancing measures. A lockdown is helpful when a combination of interventions is put in place, but lockdown alone is unlikely to reduce annual mortality or healthcare demand. ${ }^{31}$ Very recently, the WHO has outlined six categories of measures that governments need to have in place before rolling back 'lockdown' measures. ${ }^{32}$ This document provides a cross-national overview of which countries meet four of the WHO's six recommendation for relaxing physical distancing measures. According to this document, Nepal lies in the middle range (0.6) and is about ready to ease its lockdown.

Contact tracing is a key control measure for preventing further spread of infectious diseases for COVID-19.33 There is a need to scale up and train a large number of volunteers who work collaboratively across public and private agencies to stop the transmission of COVID-19. ${ }^{34}$ Countries such as South Korea have adopted contact tracing and isolating strategy and have successfully been able to manage the pandemic without being expensive. $^{35,36}$ A widespread implementation of response measures such as wearing personal protective equipment (PPE) such as face masks, following strict hygiene routine, social distancing, paid self-quarantine, and ongoing surveillance via testing and possibly phone tracking are effective in reducing transmission as well as reducing the deaths due to COVID-19. ${ }^{30}$ However, these are not cheap options for a resource-poor country like Nepal.

\section{CONCLUSION}

With rise in deaths due to non COVID related causes and negative impacts on economic and financial condition of the country, there is a need for the 
country to ease its lockdown. Nepal is about ready to ease its lockdown although the country needs to be careful in how it safely reopens the society. Contact tracing, making face mask mandatory along with social distancing measure can be an alternative to lockdown for Nepal while the country is preparing to ease its lockdown. Social distancing, hygiene, lifestyle factors and PPE measures need to continue for long term, whilst we need to keep working on the big public health issues such as poverty reduction, improving access to health service to achieve universal health coverage.

\section{REFERENCES}

1. Bastola A, Sah R, Rodriguez-Morales AJ, Lal BK, Jha $\mathrm{R}$, Ojha HC, et al. The first 2019 novel coronavirus case in Nepal. The Lancet Infectious Diseases. 2020;20(3):279-280. GoogleScholar

2. Asim $M$, Sathian B, van Teijlingen ER, Mekkodathil $A$, Subramanya SH, Simkhada P. COVID-19 Pandemic: Public health implications in Nepal. Nepal Journal of Epidemiology. 2020;10(1):817-820. GoogleScholar

3. Ministry of Health and Population. Nepal's latest updates. Ministry of Health and Population, Government of Nepal 2020. Accessed 03 May 2020. [Link]

4. Pradhan TR. Nepal goes under lockdown for a week starting 6 am Tuesday. The Kathmandu Post. March 30, 2020. Accessed 29 May 2020. [Link]

5. Nepali Times. Lockdown $=$ Breakdown - Nepalis take to social media to protest $8^{\text {th }}$ extension of coronavirus lockdown till 14 June. Accessed 31 May, 2020. [Link]

6. Ministry of Health. Nepal Demographic and Health Survey 2016. Ministry of Health, New ERA, ICF. 2017. Accessed 30 May 2020. [Link]

7. UNFPA. In Nepal, COVID-19 turning pregnancy excitement into fear. Accessed May 12, 2020. [Link]

8. One Heart Worldwide. COVID-19 updates and One Heart Response, 2020. Accessed 29 May 2020. [Link]

9. The Kathmandu Post. A 200 percent increase in maternal mortality since the lockdown began, 2020 . Accessed 28 May 2020. [Link]

10. My Republica. Suicide cases on the rise, mental health experts warn of a 'grim situation', 2020. Accessed 25 May 2020. [Link]

11. WHO. Mental health and COVID-19. 2020. Accessed 27 May 2020. [Link]

12. Xiang Y.T., Yang Y., Li W., Zhang L., Zhang Q., Cheung T., $\mathrm{Ng} \mathrm{C.H.} \mathrm{Timely} \mathrm{mental} \mathrm{health} \mathrm{care} \mathrm{for} \mathrm{the} 2019$ novel coronavirus outbreak is urgently needed. The Lancet Psychiatry. 2020;7(3):228-229. [GoogleScholar] [TheLancet]
13. Mamun M.A and Griffiths M.D. 2020. First COVID-19 suicide case in Bangladesh due to fear of COVID-19 and xenophobia: Possible suicide prevention strategies. [ResearchGate] [GoogleScholar]

14. Goyal K., Chauhan P., Chhikara K., Gupta P., Singh M.P. Fear of COVID 2019: first suicidal case in India. Asian J. Psychiatr. 2020;49:101989. [GoogleScholar] [FullText]

15. Lee J. Mental health effects of school closures during COVID-19. The Lancet Child \& Adolescent Health. 2020; 4(6): 421. [Thelancet] [GoogleScholar]

16. NSPCC. Arguments, Conflict and Family Tension during Coronavirs (COVID-19), 2020. Accessed 29 May 2020. [Link]

17. Save The Children. COVID-19: Millions of children in lockdown in Asia at risk of domestic violence, 2020. Accessed 29 May 2020. [Link]

18. The Kathmandu Post. Fears of a rise in cases of domestic violence due to the lockdown may have come to pass, 2020. Accessed 29 May 2020. [Link]

19. WOREC. 336 Cases of Violence Against Women And Girls Committed During Lockdown, 2020. Accessed 20 May 2020. [Link]

20. BBC News. Stalled vaccine programmes 'putting children's lives at risk', 2020. Accessed 30 May 2020. [Link]

21. DoHS, Ministry of Health and Population, Nepal. Interim Guidance for RMNCH services in COVID 19 Pandemic, 2020. Accessed 03 June 2020. [Link]

22. UNICEF. Disruption of child vaccination in South Asia poses an urgent threat to children's health-UNICEF, 2020. Accessed 02 June 2020. [Link]

23. UNICEF. As COVID-19 devastates already fragile health systems, over 440,000 additional children under five could die in the next six months in South Asia, without urgent action, 2020. Accessed 01 June 2020. [Link]

24. The Kathmandu Post. Patients under regular medication face shortage of medicines due to prolonged lockdown, 2020. Accessed 01 June 2020. [Link]

25. International Institute for Environment and Development. Curbing the impacts of COVID-19 on Nepal's small-scale farmers and seizing opportunities for food system reform, 2020. Accessed 03 June 2020. [Link]

26. The World Bank. Nepal must ramp up COVID-29 action to protect its people, revive economy, 2020. Accessed 03 June 2020. [Link]

27. The Kathmandu Post C. Government extends lockdown until June 14, 2020. Accessed 30 May 2020. [Link]

28. Sapkota K, Dangal G, Koirala M, Sapkota K, Poudel 
A, Dhital SR. Strategies for prevention and control of COVID-19 in Nepal. Journal of Patan Academy of Health Sciences. 2020;7(1):85-88. ResearchGate GoogleScholar

29. Ministry of Health and Population. Health Sector Emergency Response Plan- COVID-19 pandemic. Ministry of health and Population, Government of Nepal, 2020. Accessed 30 May 2020. [Link]

30. Gershon D, Lipton A, Levine H. Managing COVID-19 pandemic without destructing the economy. GoogleScholar

31. Pandey KR, Subedee A, Khanal B, Koirala B. COVID-19 control strategies and intervention effects in resource limited settings: A modelling study. MedRxiv. 2020. GoogleScholar
32. Hale $T$, Phillips $T$, Petherick A, Kira B, Angrist $B$, Aymar K, Webster S. Lockdown rollback checklist: Do countries meet WHO recommendations for rolling back lockdown? University of Oxford. Accessed 03 June 2020. [Link]

33. Eames KTD, Keeling KJ. Contact tracing and disease control. Proceedings Biological Sciences/ The Royal Society. 2003;270(1533):2565-2571. GoogleScholar

34. CDC. Coronavirus Disease 2019 - Principles of contact tracing, 2020. Accessed 01 June 2020. [Link]

35. Kennedy J. What can the UK learn from South Korea's response to COVID-19? 2020. Accessed: 28 May 2020. [Link]

36. Shahi P, Tamang PD, Rokaya YB. What can other countries learn from South Korea's COVID-19 responses?. Europasian Journal of Medical Sciences. 2020;2(1). GoogleScholar 